\title{
On the horizon: neonatal lung transplantation
}

\author{
N Scott Adzick
}

There are several congenital lung lesions that result in severe pulmonary hypoplasia and neonatal death. These malformations include congenital diaphragmatic hernia $(\mathrm{CDH})$, oligohydramnios induced pulmonary hypoplasia, and congenital cystic adenomatoid malformation of the lung. Severely affected newborns are not salvageable by current surgical techniques or medical treatment, although one new experimental approach is prenatal surgical intervention in highly selected cases. ${ }^{1-3}$ In older children respiratory failure is the final common pathway in severe cases of bronchopulmonary dysplasia, cystic fibrosis, and primary pulmonary hypertension. One potential treatment for all of these fatal problems is lung transplantation.

\section{Adult lung transplantation}

Before 1980, all 40 attempts at single lung transplantation worldwide failed. ${ }^{4}$ Over the past decade adult lung transplantation has been successfully implemented at more than $\mathbf{5 0}$ medical centres worldwide. After years of discouraging results success was obtained because of multiple factors including the availability of cyclosporin for immunosuppression and the use of the omentum to protect and revascularise the crucial bronchial anastomosis. The primary indications for lung transplantation in the adult age group are pulmonary fibrosis, emphysema, cystic fibrosis, and Eisenmenger's syndrome. Results have steadily improved with experience and the overall one year survival was $79 \%$ in a series of 66 patients reported by the pioneering group at Washington University in St Louis. ${ }^{5}$ Single lung transplantation may partially supplant heart-lung transplantation as the lung is a 'spare' organ whose use does not preclude use of the heart and the contralateral lung for other patients. However, potential recipients with suppurative lung disease such as cystic fibrosis require either bilateral sequential lung transplants in which both infected lungs are replaced at one setting or an en-bloc heart-lung transplant. In the latter circumstance the recipient heart can then be donated to another patient-the 'domino' operation. ${ }^{6}$

Tetal Treatment Program and the Department of California, San Francisco Correspondence to: Dr N Scott Adzick, Department of Surgery, Department of Surgery, University of California, San Francisco, 513 Parnass Avenue, Room HSE-585,

CA 94143-0570, USA.
Although the experience with lung transplantation in adults has been very encouraging, the lung transplantation effort in children is just beginning. Thirty four paediatric lung trans- plants are recorded in the International Lung Transplant Registry at Washington University and the indications included severe bronchopulmonary dysplasia, cystic fibrosis, and refractory pulmonary hypertension. The youngest recipient was 16 months of age, and the overall actuarial one year survival was $60 \%$. However, paediatric lung transplantation is hampered by the paucity of potential donors and a lack of understanding of many physiological responses to transplantation in immature recipients. Cadaveric or living related donation of a reduced size lung (pulmonary lobe or segment) may help solve the donor shortage problem for lung transplantation in infants and children. It is essential that experimental studies be crafted to address some of the biological questions.

\section{Neonatal lung transplantation}

For neonates with fatal pulmonary hypoplasia, biological tissue replacement is the only potentially satisfactory solution. The donor lung graft must be able to grow and adapt to increasing functional demand over the long potential lifespan of the young recipient. But the logistics of lung transplantation are particularly demanding for the neonatal recipient in whom rapid respiratory failure and short term extracorporeal membrane oxygenation (ECMO) support make the 'time window' for transplantation narrow. Because so few babies die in circumstances allowing organ donation, it is unlikely that an appropriate cadaver whole lung will be found during the limited time that the sick neonate is salvageable on ECMO.

Living related organ donation is a clinical reality in paediatric renal and liver transplantation, ${ }^{7} 8$ and it represents the principal alternative for bone marrow transplant recipients. ${ }^{9}$ This source of donor tissue has resulted in enhanced graft survival and diminished time on transplant waiting lists. Living related donation of a reduced size lung (either lobe or segment) may help solve the donor shortage problem for paediatric lung transplantaion. Donor pulmonary segmentectomy or lobectomy are straightforward surgical procedures. In contrast to cadaver donation, living related donation should be logistically simple, less costly, and readily available. In addition, it may result in enhanced graft survival due to potential immunological advantages. This concept has recently been tested clinically by the group at Stanford University. A 12 year old girl who was 
afflicted with end stage bronchopulmonary dysplasia had her right lung replaced with the upper lobe from her mother. ${ }^{10}$ She is doing well one year after transplantation.

The principal candidate for neonatal lung transplantation is the baby with $\mathrm{CDH}$ with severe pulmonary hypoplasia. Recent studies have defined prognostic factors for babies with CDH diagnosed before birth. ${ }^{11}$ Although ECMO has been a major advance in the treatment of respiratory insufficiency in neonates, some babies with $\mathrm{CDH}$ are still unsalvageable due to the severity of their pulmonary hypoplasia. ${ }^{12}$ Using ECMO as a 'bridge' to lung transplantation in severely ill babies with diaphragmatic hernia would permit time to find a donor, perform the lung transplant, and surgically repair the diaphragmatic defect during the 10-14 day period when the baby can be maintained on the ECMO circuit. Transplantation of a reduced size lung (lobe or segment) for severe pulmonary hypoplasia offers a new approach for infants who are otherwise doomed.

There are several other congenital diseases that result in inadequate gas exchange at birth including oligohydramnios induced pulmonary hypoplasia, severe cases of congenital cystic adenomatoid malformation of the lung, and irreversible primary pulmonary hypertension. Recent clinical confirmation of the reduced size lung transplantation concept for neonates was provided by another case from Stanford University (KP Van Meurs et al, presented at the Children's Hospital National Medical Center ECMO Conference, 1991). A newborn with severe pulmonary hypertension could not be weaned from ECMO support. The left upper lobe and lingula from a 2 year old cadaveric donor were transplanted while the baby was on ECMO, with immediate weaning and decannulation. The baby initially did extremely well, but unfortunately died from an overwhelming rejection episode at age 8 months.

Before attempting lung replacement in neonates, it is necessary to clarify the anatomical, technical, physiological, and immunological problems in an animal model. To evaluate these considerations, our group developed a model of pulmonary lobar transplantation in neonatal pigs and studied pulmonary function and hemodynamics after transplanting the left lower lobe from a more mature (20-30 kg) donor to a neonatal $(5 \mathrm{~kg})$ recipient. The recipient's left atrial and pulmonary arterial pressures, cardiac output, pulmonary vascular resistance, and pulmonary static compliance were measured before and after left lower lobe transplantation. ${ }^{13}$ In a separate series of experiments, the haemodynamic conditions of $\mathrm{CDH}$ were simulated by occlusion of the right (contralateral) pulmonary artery. ${ }^{14}$ We found that lobar transplantation is technically feasible and physiologically sound. The static compliance of the lobar transplant is far greater than that of the native neonatal lung, and the transplanted lobe can accept the entire cardiac output during contralateral pulmonary arterial occlusion. Subsequent studies in a chronically immunosuppressed piglet model established the technique of an intercostal muscle flap to protect the bronchial anastomosis and used the gastrointestinal stapling device (US Surgical Corp) to 'sculpt' the apical segment of the left upper lobe from a $60 \mathrm{~kg}$ donor to fit into the neonatal recipient. ${ }^{15}$ Other investigators have developed similar reduced size lung transplant techniques in beagle puppy and neonatal sheep animal models. ${ }^{16} 17$ The ability of an immature lung graft to grow in an immature recipient has been demonstrated in weanling pigs. ${ }^{18}$

A series of human adult and neonatal cadaver thoracic dissections were performed to determine the adult pulmonary lobe or segment with the proper size, orientation, and vascular and bronchial anatomy for use as a neonatal lung transplant. ${ }^{15}$ The adult right middle lobe was found to be the best candidate for left lung replacement in the neonate with $\mathrm{CDH}$. The adult right middle lobe; once removed, can be rotated $180^{\circ}$ around its superior-inferior axis and the vessels and bronchus align well in the left chest of the neonate. The right middle lobe is the proper size to fill the neonatal left chest. If necessary, it can be sculpted with a stapling device to solve size disparity problems. The evaluation of the other adult lobes and segments revealed problems with vascular anatomy, vascular variability, size, or bronchial geometry which prevented consideration for neonatal lung replacement. It appears that the technical aspects of the lung transplantation operation will not be the limiting factor for success.

Consideration of lung transplantation in neonates and children provokes many unanswered questions. The growth potential of a denervated mature lobar graft in a neonatal environment is a major unresolved issue. What constitutes optimal immunosuppression in the neonate and how is it altered by growth and development? Likewise, the effects of chronic immunosuppression on the infant's growth and development is an unchartered area. Can chronic airway injury related to pulmonary rejection and infection be prevented? What is the best method to detect rejection in these patients as the transbronchial biopsy technique used in adults will probably not be applicable in babies? Finally, the recovery potential of the contralateral hypoplastic lung in babies with $\mathrm{CDH}$ after lung transplantation is an area worthy of investigation. Even if growth of the mature allograft does not occur, the transplant may function as a biological assist device until the remaining contralateral native lung tissue undergoes further alveolar growth. Thereafter, the allograft could be removed and the immunosuppression stopped. Recent encouraging clinical developments in neonatal transplantation, including cardiac transplantation for hypoplastic left heart syndrome ${ }^{19}$ and successful transplantation of segmental liver grafts from living related adult donors into infant recipients with biliary atresia, ${ }^{8}$ have made some of these questions more pressing. The outcome for tiny recipients of lung transplants will depend upon the answers to these questions.

I Harrison MR, Adzick NS, Longaker MT, et al. Successful repair in utero of a fetal diaphragmatic hernia after removal of herniated viscera from the left thorax. $N E n g l \not \mathcal{M} e d$ 1990;322:1582-4.

2 Harrison MR, Adzick NS, Jennings RW, et al. Antenatal 
intervention for congenital cystic adenomatoid malformation. Lancet 1990;336:965-7.

3 Crombleholme TM, Harrison MR, Langer JC, et al. Early experience with open fetal surgery for congenital hydronephrosis. I Pediatr Surg 1988;23:1114-6.

4 Cooper JD. The evolution of techniques and indications for lung transplantation. Ann Surg 1990;213:249-56.

5 Trulock EP, Cooper JD, Kaiser LR, et al. The Washington University-Barnes Hospital experience with lung transplantation. $\mathscr{f} A M A$ 1991;266:1943-6.

6 Smyth RL, Higenbottam T, Scott $M$, Wallwork J. The current stage of lung transplantation for cystic fibrosis. current stage of lung

7 Najarian J, Frey D, Matas A, et al. Renal transplantation in infants. Ann Surg 1990;212:353-65.

8 Broelsch CE, Whitington PF, Emond JC, et al. Liver transplantation from living related donors. Ann Surg transplantation fror

9 Vowels MR, Lam PTR, Brown R. Bone marrow transplantation: a review of a programme and its first 100 patients Med f A A st 1990;153:580-4.

10 Goldsmith MF. Mother to child: first living donor lung transplant. FAMA 1990;264:272

11 Adzick NS, Harrison MR, Glick PL, et al. Diaphragmatic hernia in the fetus: prenatal diagnosis and outcome in 94 cases. 7 Pediatr Surg 1985;20:357-61.
12 Adzick NS, Vacanti JP, Lillehei CW, et al. Fetal diaphragmatic hernia: ultrasound diagnosis and clinical outcome in 38 cases from a single medical center. $\mathcal{f}$ Pediatr Surg 1989;24:654-8.

13 Crombleholme TM, Adzick NS, Longaker MT, et al. Reduced-size lung transplantation in neonatal swine: technique and short-term physiologic response. Ann Thorac Surg 1990;49:55-60.

14 Crombleholme TM, Adzick NS, Hardy K, et al. Pulmonary lobar transplantation in neonatal swine A model for treatment of congenital diaphragmatic hernia. $\mathcal{J}$ Pediat Surg 1990;25:11-8.

15 Jennings RW, Adzick NS, Harrison MR. Adult to neonate human lung transplant: anatomic considerations. $\mathcal{F}$ Pediatr

Surg (in press).
16 Backer CL, Ohtake S, Zales VR, et al. Living-related llobar lung transplantation in beagle puppies. I Pediatr Surg 1991.27:429-32.

17 Lillehei CW, Evarts E, Shamberger RC. Reduced-sized lung transplantation. $\mathcal{F}$ Pediatr Surg (in press).

18 Haverich A, Dammenhayn L, Demrtzis $\dot{S}$, et al. Lung rowth after experimental pulmonary transplantation. Foumal of Heart and Lung Transplantation 1991;10:288-95.

19 Bailey LL, Assad AN, Trimm RF, et al. Orthotopic ransplantation during early infancy as therapy for incurable congenital heart disease. Ann Surg 1988;208:279-86. 